$\xi=1$ 国

\title{
Development of a mathematics learning tool using inventive principle
}

\author{
Farah Marinah Aminuddin ${ }^{1}$, Anis Shafiqah Radzuan ${ }^{1}$, Aznilinda Zainuddin ${ }^{1}$, Ummi Suraya Shaharuddin ${ }^{2}$, \\ Munirah Onn ${ }^{3}$, Suhana Mohamed ${ }^{4}$, Herda Balqis Ismail ${ }^{5}$, Atiqah Hamizah Mohd Nordin ${ }^{1}$, \\ Rijalul Fahmi Mustapa ${ }^{1}$ \\ ${ }^{1}$ Faculty of Electrical Engineering, Universiti Teknologi MARA, 81750 Masai, Johor, Malaysia, \\ ${ }^{2}$ Faculty of Information Science and Engineering, Management and Science University, 40100 Shah Alam, Selangor, Malaysia \\ ${ }^{3}$ Faculty of Applied Sciences, Universiti Teknologi MARA, 81750 Masai, Johor, Malaysia \\ ${ }^{4}$ Faculty of Business and Management, Universiti Teknologi MARA, 81750 Masai, Johor, Malaysia \\ ${ }^{5}$ Faculty of Civil Engineering, Universiti Teknologi MARA, 81750 Masai, Johor, Malaysia \\ *Corresponding author E-mail: aznilinda@johor.uitm.edu.my
}

\begin{abstract}
Gamification learning is proven to be an educational approach to nurture student's interest to learn by using the game invented and designed with their special elements in learning environments. This project applies a systematic design approach using inventive principles to develop mathematics learning tools for primary school students. A product that gives real experiential learning to the students with versatile and innovative values developed using inventive principles, ensuring that kids have the experience of learning by doing, this product helps to develop new skills, new attitudes and new ways of thinking. Four different inventive principles which are self-service, feedback, color change and dynamization are used to produce the final product which is simpler, faster and cheaper. Since there is a significant growth of the economic world, the revolutionary is sure to occur. The scenario indicates that the possibility of ineffective teaching method and tradi-tional method of teaching are no longer suitable for this generation of kids. It attracts kids to learn mathematics using gamification as a plat-form. The project uses a color sensor that replaces the numbers. The color sensor then sends the information to the microcontroller. The final working prototypes named MEGO acronym for Mathematics Education Go.
\end{abstract}

Keywords: Color Sensor; Microcontroller; Arduino Micro; Inventive Problem Solving; Systematic Innovation; TRIZ; Inventive Principle.

\section{Introduction}

The Russian acronym TRIZ translated as theory of inventive problem solving is the new systematic problem-solving approach. It was established by Genrich Altshuller and his colleagues based on the study of patents of problems and solutions. TRIZ provides repeatability, predictability and reliability due to its structure and algorithmic approach [1]. It develops individual and team's ability to accomplish decision making process, range from simple to complex. TRIZ can be adopted to achieve another level of innovation through its systematic solving and inventive principle approach.

MEGO is an acronym for Mathematics Education Go, which is the name of the project. This project involves the use of the color sensor and the questions are set from basic level using the Android platform. It can be developed in future to include critical thinking sets of questions. After seeing the falling of the young generation academically, thus motivated the author to build this project. The objective of this project is to build a prototype of MEGO, Mathematics Education Go using Arduino Micro as the microcontroller. Other than that, the objective is to access the effectiveness of the MEGO system in preventing the math's performance of children at age 5 and above becoming much worst.

The Trends in International Mathematics and Science Study (TIMSS) in 2015 reported that Malaysia ranked $23^{\text {rd }}$ in mathematics at TIMSS, a global achievements test while Singapore, the neighboring country ranks number 1 among 57 countries [2]. Conventional formal classroom may lead to a bored environment which leads to the neglecting the importance of the mathematics thinking skills [3]. With the era of high technology and gadgets, students will prefer all entertainment and knowledge explored by using the techno gadgets. However, video games this day have less beneficial learning content and not to mentioned full of violence and more focusing for entertaining purposes. Nowadays, most parents prefer to allow their children to use gadgets as one of time filling activity. The parents forget that the fact is children at age 5 and above have the biggest capacity of memory available thus make their age suitable to learn new things [4]. This ignorance leads to gadget addiction.

There are several projects done to capture the interest of kids in mathematics through coding and gamification. It substitutes the current traditional method of teaching by using a device as a teaching tool to make the mathematics topic to be more interesting. The inference of literature review is discussed herein [5-10]. Osmo Coding using Arduino platform developed by Simon Crisp [5]. In this study, the researcher used Reflective Artificial Intelligence (AI), a phase where he created to define the process that allows the iPad to make sense of what it sees. Reflective AI comprises two components. Firstly, the red Osmo reflector (a mirror). Secondly, the computer vision algorithms that process the data. Working together, the reflector and the computer vision software give the iPad the ability to integrate physical objects into 
his games in real time. Other tools developed-[6] is a mobile application that is designed to ease the difficulty encountered during any exam process. It is a mobile application that can also be applied in education gamification tools. DIY Android Bluetooth PC Gamepad also used Arduino and was developed by planet leak [7], they use Arduino to make android interact with the existing games. The smartphone will replace control to play the games for example or create a control player for PC games for smooth playing. Coder game and apps: Teaching Kids Coding with Games is an Arduino-compatible microcontroller developed by KosmoBit [8]. In this study, the Arduino is already with Bluetooth, cable, rotary control wheel, circuit board, gamepad housing, two push buttons, motion sensor, temperature sensor, sound sensor, light sensor and Code Gamer Apps. It needs a tablet or smartphone running iOS or Android. Their game use sensors to control the game with their innovative gamepad.

Game of Life also known as Life, is a cellular automaton and use Arduino Graphical Liquid-Crystal Display (GLCD) as a microcontroller developed by John Horton Conway [9]. He makes an effort to find a hypothetical machine that could build copies of itself. He thrived when he found a mathematical model with very complicated rules on a rectangular grid. The game has two possible states, alive and dead. Speed Math Game with Arduino is a three-level quiz game developed by [10]. It uses Arduino One but can also use another type of Arduino. It has three levels which are easy, medium and hard. The comfortable level shows numbers between 1 and 10. In the medium level, the first operand of the operation is a number between 50 and 99 and the second operand is a number between 1 and 10, while the hard level shows numbers between 50 and 99 . This game test how fast the skills of player in solving mathematics. Arduino is a well-known open-source microcontroller widely used in electronic prototyping. It has been widely used in developing educational tools, especially for higher learning level [11].

The difference between Osmo and MEGO is that Osmo has separated hardware to their application. Osmo Artificial Intelligence only compatible with Apple System which is iOS. Not only the device is expensive, the main component or hardware is also expensive. Their games also needed payment in the Apple Store. MEGO do not have separated hardware, and the application is free of charge. The difference between DIY Android Bluetooth PC Gamepad and MEGO is that MEGO is for education purpose, while DIY Android Bluetooth PC Gamepad is for entertainment only. The difference between Coder game and apps: Teaching Kids Coding with Games and MEGO is that it used light and sound sensor, while MEGO used the color sensor. The difference between Game of Life and MEGO is that the game developed by John Horton Conway is suitable for adults with critical thinking while MEGO target kids at aged 5 to 12 years old. The difference between Speed Math Game and MEGO is that the game tests how fast the player can solve the puzzle, while MEGO test the solving skills of the player.

\section{Methodology}

In this study, Inventive Problem Solving, TRIZ is used to solve the problem statement. TRIZ helps to eliminate psychological inertia. The process is represented in Figure 1. It starts with identifying the problem by providing a clear problem statement. Upon a precise identification of the problem statement, it needs to be rephrased and defined to establish a problem statement that will be used in the Cause and Effect Chain Analysis (CECA). During the CECA process, we can identify few causes. The next step is to identify any contradiction in solving the cause. It could be Engineering Contradiction (EC) or Physical Contradiction (PC). A proposed idea to solve EC is then referred to the Contradiction Matrix, which will lead to a proposed inventive principle. While for PC, Table 1 shows the inventive principle that can be used.

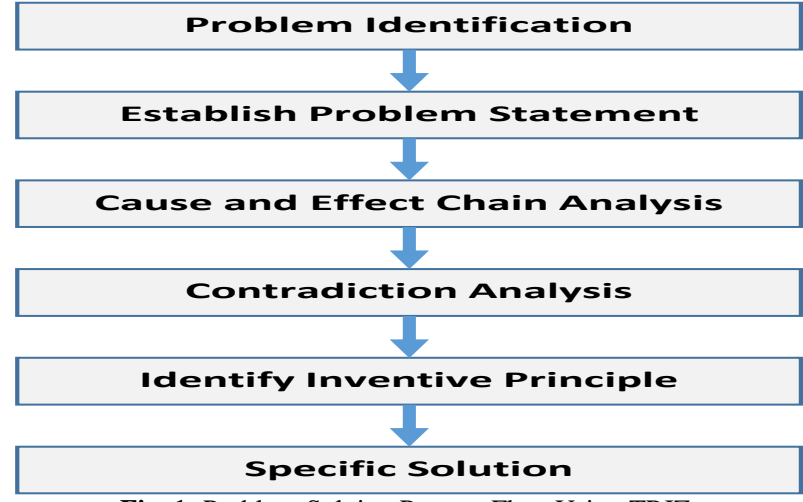

Fig. 1: Problem-Solving Process Flow Using TRIZ.

Table 1: Seven Inventive Principle for PC

Inventive Principles Used for Physical Contradiction

\begin{tabular}{ll}
\hline Separation in Time & Separation in Space \\
15. Dynamics & 1. Segmentation \\
10. Prior Action & 2. Taking out \\
19. Periodic Action & 3. Local quality \\
11. Beforehand cushioning & 17. Another dimension \\
16. Partial or excessive action & 13. The other way around \\
21. Skipping & 14. Curvature \\
26. Copying & 7. Nested doll \\
18. Mechanical vibration & 30. Flexible shells/ thin films \\
37. Thermal expansion & 4. Asymmetry \\
34. Discarding \& recovering & 24. Intermediary \\
9. Prior counter-action & 26. Copying \\
20. Continuity of useful action &
\end{tabular}

The established problem statement is lack of interest in mathematics among $1^{\text {st }}$ grade to $6^{\text {th }}$ grade students.

\subsection{Cause and effect chain analysis}

In TRIZ, CECA has actively used for seeing-through the essential vital problems. The process taken in CECA is as below. It needs to be done in a team of a brainstorming session.

i) All team members must agree to the established problem statement. Problems that are too general and vague can make it hard for the team to identify an apparent cause.

ii) Start the brainstorming session on what are the likely causes and then categorize them into groups. Add or drop any categories as needed when generating the causes.

iii) Continue to brainstorm and generate a list of causes and fill them in the appropriate categories or branches by asking "Why?" and "Why else?" for until a potential cause is seen. Check the chain of causes if it makes sense and makes changes if needed.

iv) Get agreement from the team members to choose several areas they feel are most likely causes and remove the unlikely causes.

v) Validate hypothesis to confirm the likely cause and proceed to implement the solution.

Figure 2 is the CECA for the specific case. The finalized root cause is ticked with the green tick symbol.

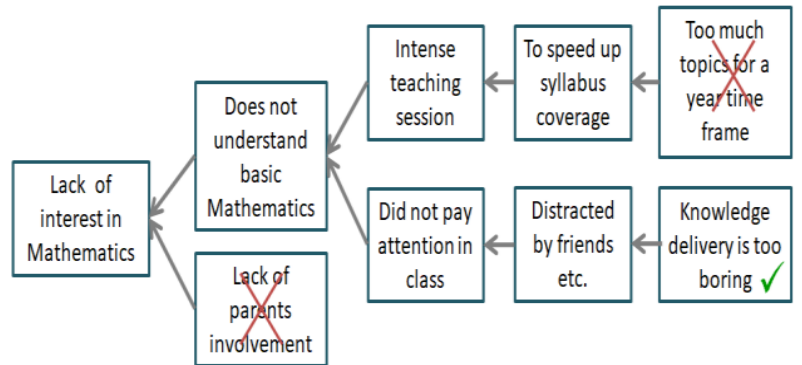

Fig. 2: CECA for Problem Statement: Lack Of Interest in Mathematics among $1^{\text {st }}$ Grade to $6^{\text {th }}$-Grade Students. 
From the CECA analyzed, the principal caused by a lack of interest in mathematics is due to a boredom environment during the lesson. This may be caused by teachers in low achieving classrooms, where teachers might teach this topic less ambitiously and avoid arguing on a sophisticated level.

\subsection{Contradiction matrix}

Contradiction observed from the CECA is an Engineering Contradiction with below statements:

a) If a teacher changes delivery method, then the class will be interesting, but the teacher needs new material for the new delivery method.

b) If a teacher changes delivery method, then the class will be interesting, but both students and teacher need time to adapt.

For statement $\mathrm{A}$, the worsening parameter will be parameter 35: ease of operation and improving parameter is parameter 39: productivity. Moreover, for statement $\mathrm{B}$, the worsening parameter will be parameter 35: adaptability and improving parameter is parameter 39: Productivity. Referring to the contradiction matrix, the proposed inventive principles to solve the problem summarized in Table 2.

By having 2 possible Engineering Contradiction as above, inventive principle 1: segmentation and 28: mechanic substitution is both proposed as the possible solution. After a few sessions of discussion, inventive principle no. 28 brings the idea to substitute the current traditional method of teaching by using a device as a teaching aid to make the mathematics topic to be more interesting. The device called MEGO developed with a sensory elements.

This project is a new innovation break through that differs to conventional teaching approach. It is not only easy to play with and a very user-friendly game, this project can be played anywhere since internet connection is not required. The existing project will be limited to mathematics subject with the target user is suitable for 5 to 12-year-old kids. The games can be played using smartphone with Bluetooth connection. The main aim of this project is to provide an interactive element that can motivate students to venture and explore mathematics. It can also create an opportunity for kids who may develop an interest in coding and computer skills.

Table 2: Summarized Proposed Inventive Principle

\begin{tabular}{|c|c|c|c|}
\hline & $\begin{array}{l}\text { Worsening } \mathrm{Pa}- \\
\text { rameter }\end{array}$ & $\begin{array}{l}\text { Improving } \\
\text { Parameter }\end{array}$ & Proposed Inventive Principle and Improvement Plan \\
\hline $\begin{array}{l}\text { A: If a teacher } \\
\text { changes delivery } \\
\text { method, then the } \\
\text { class will be } \\
\text { interesting, } \\
\text { but the teacher } \\
\text { needs new } \\
\text { material for the } \\
\text { new delivery } \\
\text { Method. }\end{array}$ & $\begin{array}{l}\text { 33: Ease of Oper- } \\
\text { ation }\end{array}$ & $\begin{array}{l}\text { 39: Productivi- } \\
\text { ty }\end{array}$ & $\begin{array}{l}\text { 1: Segmentation (Divide into independent parts) 7: Nested Doll (e.g., Russian Doll, camera } \\
\text { tripod) 28: Mechanics Substitution (Change mechanical to Electrical, Magnetic, Optical, } \\
\text { Acoustic, Sensory Fields) 19: Periodic Action (Pulsate, Change magnitude or Frequency) }\end{array}$ \\
\hline $\begin{array}{l}\text { B: If a teacher } \\
\text { change delivery } \\
\text { method, then the } \\
\text { class will be } \\
\text { interesting, but } \\
\text { both students } \\
\text { and teacher } \\
\text { need time } \\
\text { to adapt. }\end{array}$ & $\begin{array}{l}\text { 35: Adaptability } \\
\text { or Versatility }\end{array}$ & $\begin{array}{l}\text { 39: Productivi- } \\
\text { ty }\end{array}$ & $\begin{array}{l}\text { 1: Segmentation (Divide into independent parts) 35: Parameter Change (e.g., flexibility, densi- } \\
\text { ty, geometry) 28: Mechanics Substitution (Change mechanical to Electrical, Magnetic, } \\
\text { Optical, Acoustic, Sensory Fields) 37: Thermal Expansion (e.g., bi-metallic sensor) }\end{array}$ \\
\hline
\end{tabular}

\section{Results and discussion}

\subsection{System architecture}

Figure 3 shows the block diagram of the MEGO system. Figure 4 shows the Schematic diagram of the MEGO system. The main components are Color Sensor (TCS34725), Bluetooth Module (HC-05), Tower Pro Micro RC Servo Motor 9G SG90 (180 degrees), Dot Matrix 8x8 Display (MX7219) and Arduino Micro as the microcontroller.

A set of the number has been set to correspond to a specific color (example 1 with red). When the corresponded colored number block is put on top of the color sensor, it will detect the data and send it to Arduino Micro. Arduino will then deliver the data to the apps that were created using thinkable application. Then, it will send the data to the Servo Motor and the dot matrix display. The interaction of the Servo Motor and the dot matrix display
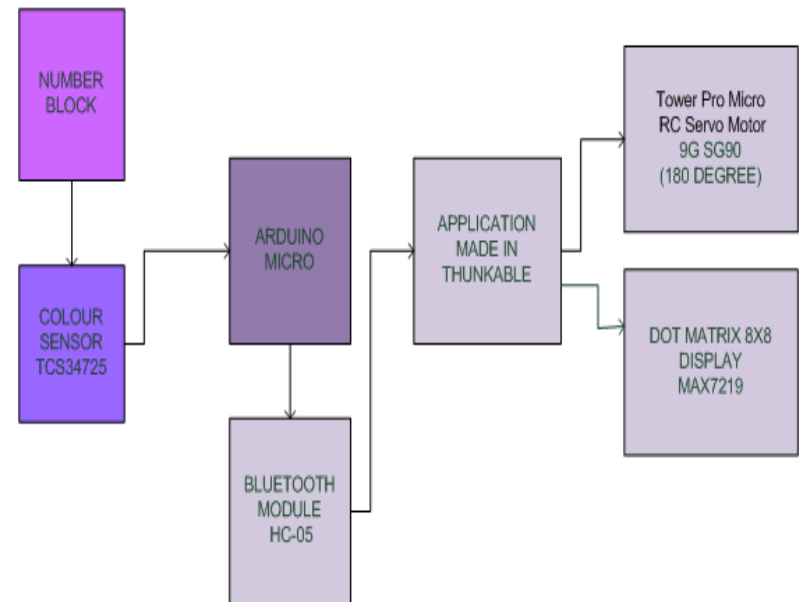
influenced by the answered question.

Fig. 3: Block Diagram of MEGO System. 


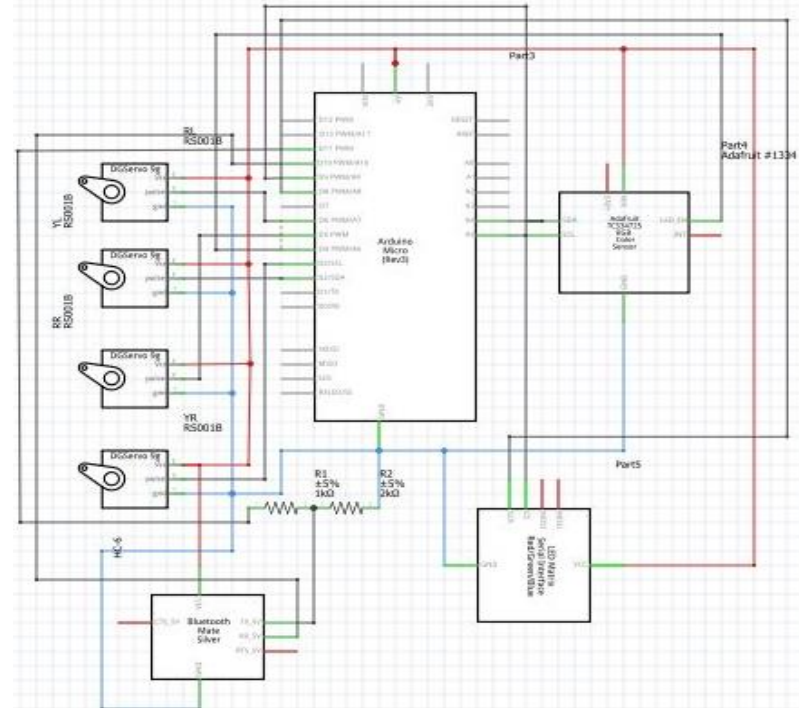

Fig. 4: Schematic Diagram of MEGO System.

\subsection{Colour sensor TCS34725}

Colour Sensor TCS34725 is constructed to extract the color chromaticity and intensity of ambient light meticulously. It caters a digital output with a resolution of 16 bit. It has an $8 \times 2$ array of filtered resolution, control function on a single monolithic CMOS integrated circuit and an analog-to-digital converter. It also has 16 photodiodes, 4 of each set of filters which is red filters, blue filters, green filters and clear filters. The synchronization input pin function is to provide precise synchronous conversion control.

\subsection{HC-05 Bluetooth}

HC-05 is a Bluetooth module created for transparent wireless serial communication. It has two work modes; the command mode and data mode. The data mode activated by the on-board push button. The command mode will activate if the push button is pressed. The module also can reinvigorate by the user to work as a master Bluetooth by using a set of AT commands. It functions with power supply voltage of 3.6 V DC to [6] V DC.

\subsection{Arduino micro}

Arduino Micro is a type of microcontroller. It has 20 digital in put/output pins in which 7 used Pulse Width Modulation (PWM) outputs and 12 as analog inputs. It also has a $16 \mathrm{MHz}$ crystal oscillator, in-circuit serial programming (ICSP) header, a micro USB connection and a reset button. To get the Arduino Micro started, simply connect it to a computer with a micro USB. The form factor of the Arduino Micro enables it to be placed on a breadboard and because of the built-in USB communication, the micro eliminates the usage of a secondary processor.

\subsection{Tower pro RC servo motor 9G SG90 (180 degrees)}

The tower pro micro Radio Control (RC) servo motor grant decisive supervision of velocity, angular position and acceleration. This specific servo motor allows 180 degrees of movement.

\subsection{Dot matrix 8x8 display (MX7219)}

The function of matrix display is to display information on various of an object such as machines, railway departure indicators, clocks and others. It required a simple display device with limited resolution. It consists of mechanical indicators, which will arrange in a rectangular configuration. It can be done by switching the on/off selected lights, graphics or text which then displayed on the dot matrix. It then converts the instruction from a processor into signals.

\subsection{Game design}

First, the player will open the MEGO application from the smartphone. When the player starts the game, the Bluetooth connection between the smartphone and tablet which enable it to received data from the Arduino. The first question is then displayed on the screen. The player will put the number block correspond to the correct color that has been set at the color sensor. The data is then sent to the application. If the answer is right, then the screen will display the happy face and the robot will dance while if the answer is wrong the screen will display the sad face. Then, the player will press the next button to display the next question.

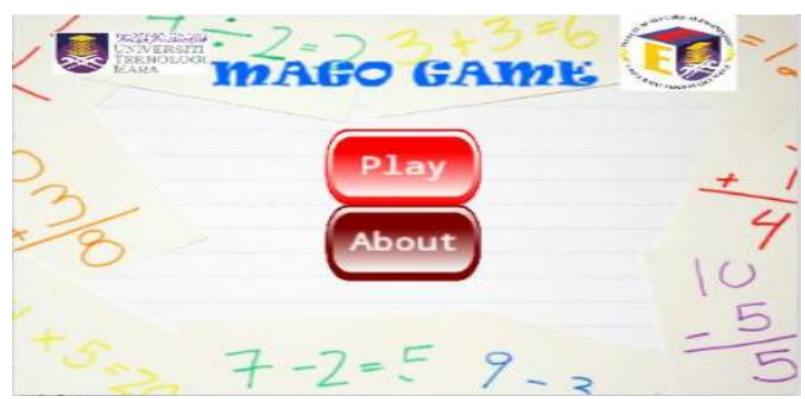

Fig. 5: The Front Page of the MEGO Apps.

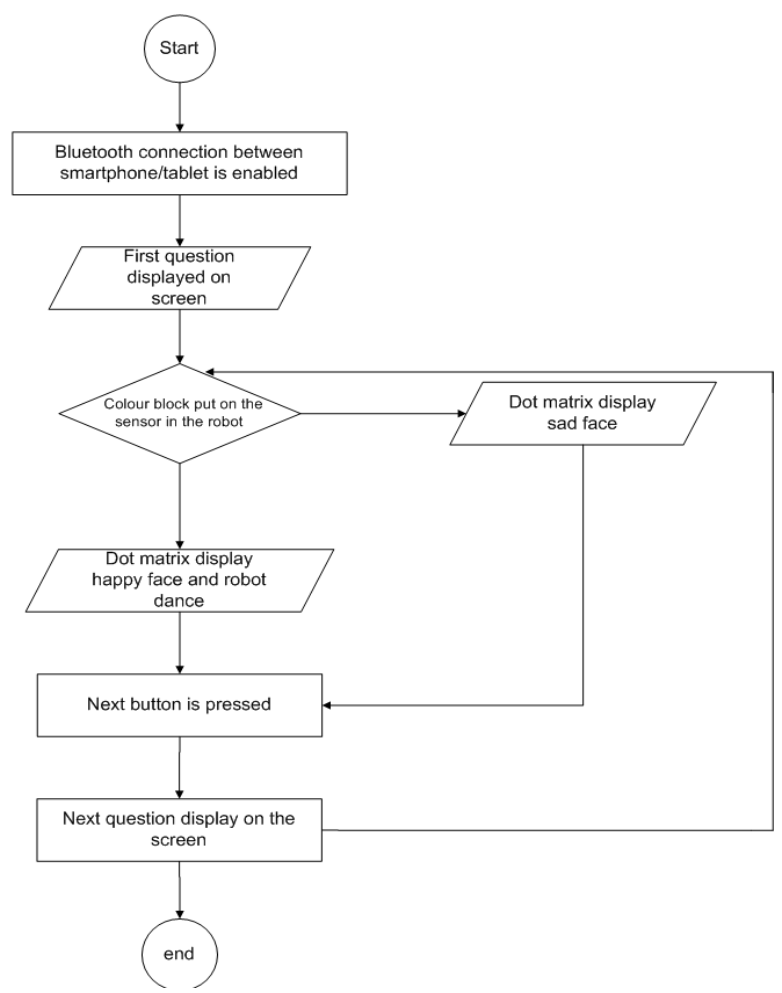

Fig.6: Flowchart of the Games System.

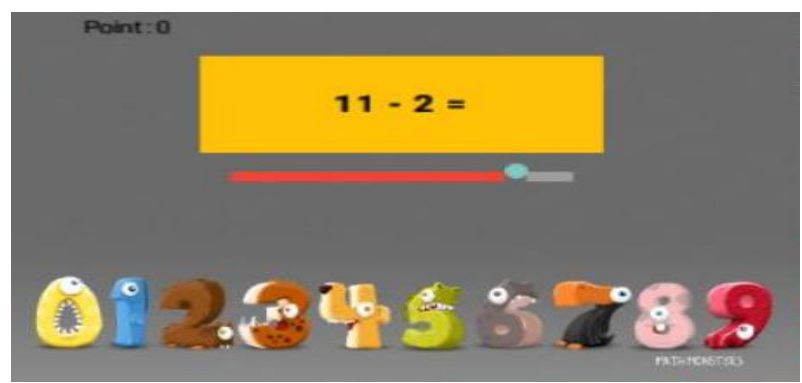

Fig. 7: The First Level Basic Question in MEGO.

\subsection{The block editor}

The block editor acts as the games coding. It has a built-in drawer to find the behavior that we want to add to our app and drag them 
to the Blocks Viewer. The component-specific drawers are to find blocks for behavior for specific components and drag them to the block viewer.

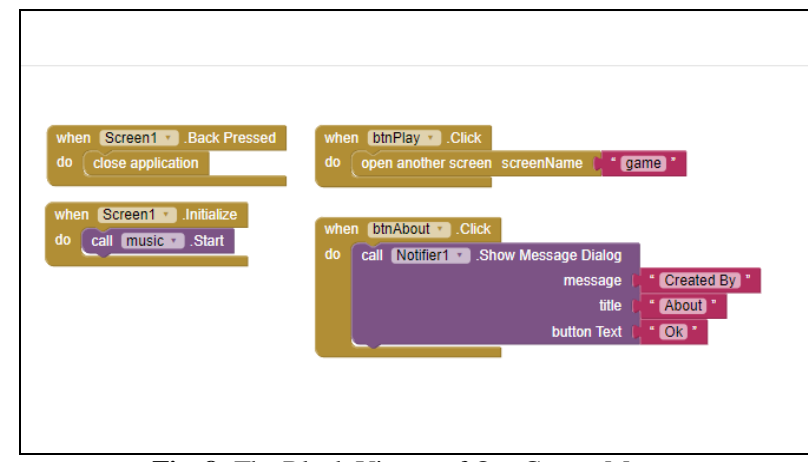

Fig. 8: The Block Viewer of Our Games Menu.

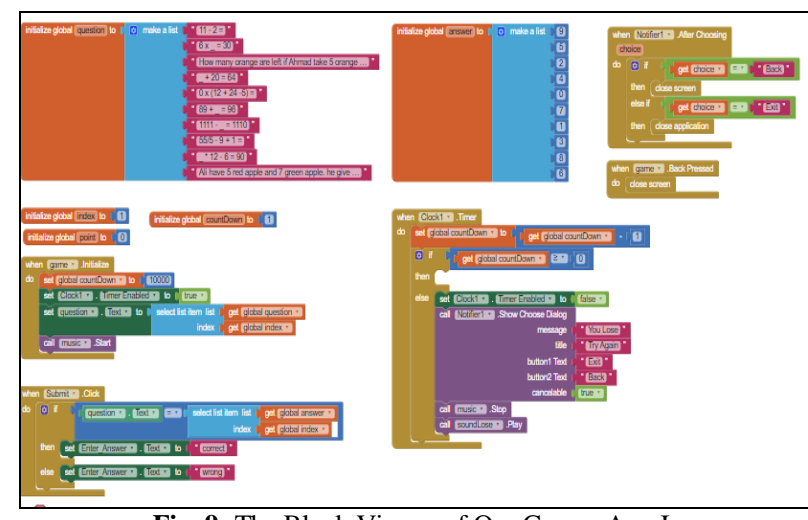

Fig. 9: The Block Viewer of Our Games App I.

In designing the app for the kid, we used Thunkable website. We declared variables for the list of math question and current math question. Then, set the index value for current math question as 1 . The index value for current math question will be used to select the mathematics question and determine the answer submitted either it is right or wrong.

Then, set the sequence of operations for when the next button or answer button is pushed. The sequence of operation for both is different since the answer button function to determine either the answer is right or wrong, while the next button functions to display the next question on the screen. So, once the next button is pushed, the answer submitted will be compared with the actual answer to determine either the answer is right or wrong.

The index value of the current question is used to select the actual answer from the answer list. If the submitted answer is equal to the actual answer, the text 'Right' will be displayed on the screen; servo will be moving, and dot matrix show the symbol '^^.' If the answer submitted is not same as the actual answer, the text 'Wrong' will be displayed instead.

For the next button operation sequence, set them to display next question on the screen by adding the index value for the current question with 1 . With the increased index value, the question is displayed will be the next question from the list. If the answer button is pushed, using the increased index value for a current question, the next answer is selected from the answer list, either if it is right or wrong. However, since the number of questions is limited, so set it when the index value is equal to the total number of question, the index value will become zero.

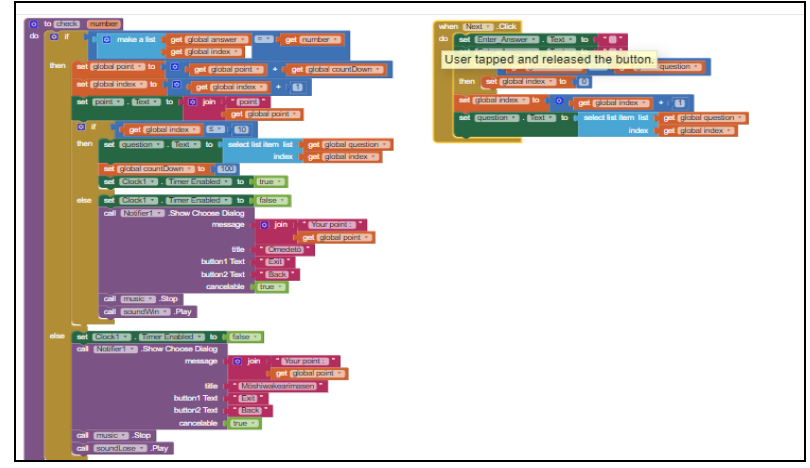

Fig. 10: The Block Viewer of Our Games App II.

\subsection{Connect the app to arduino}

After being able to make the hardware to recognize the different value of different resistors, it is time to send the date from what the Arduino received and send to the Android App. Few ways to do it; first by using Wi-Fi, but it needs its module. Also, understanding the module would take some time and would be quite complicated, especially with the limited time given to finish this project. Thus, it then decided on this project, Bluetooth module HC-05 used as a replacement for the transmitter to send the data from Arduino to Android App. Though the Bluetooth Module needs some timing to configure, all of its default settings including the password and the name of the Bluetooth alias will be used.

To transmit the data from the Arduino to the Android App was not entirely tricky, since it will send whatever output the Arduino come up with. To that, 'Serial.print' The command added into the Arduino software, and when it connects to the Bluetooth Module, it will transmit the data to the Android App. Luckily, the Bluetooth Module only needed to send in the text from Arduino 'Serial.print' to the Android App and not assign the Module to do specific actions which would be more difficult. The results of the circuit with the Bluetooth Module and the coding used for the Bluetooth Module at the MIT App Inventor seen below.

3.10. Hardware

The idea of the hardware for this project is only to make it able to differentiate number zero until nine. Since each number have a different unit, this required ten same electrical components with ten different values, so that the Arduino can identify those number without accidentally mistaken it for one another. After putting some final thoughts, different types of color are used as the component that will play the role as number zero until nine with different values of frequency respectively.

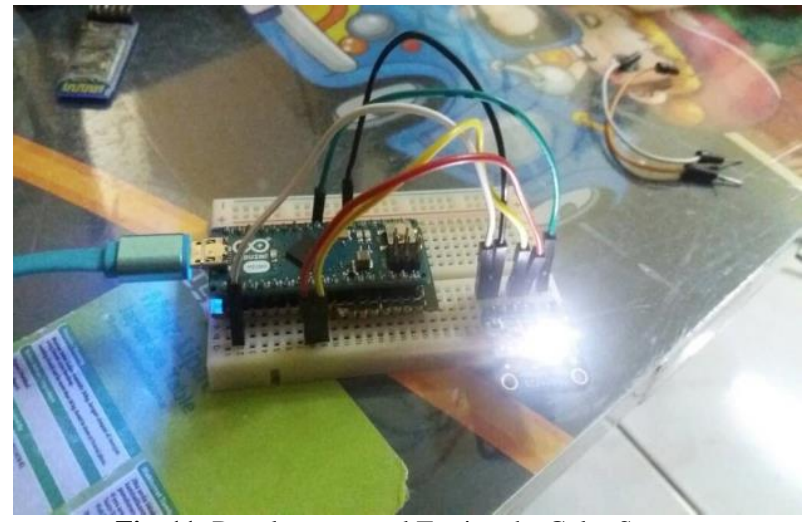

Fig. 11: Development and Testing the Color Sensor. 


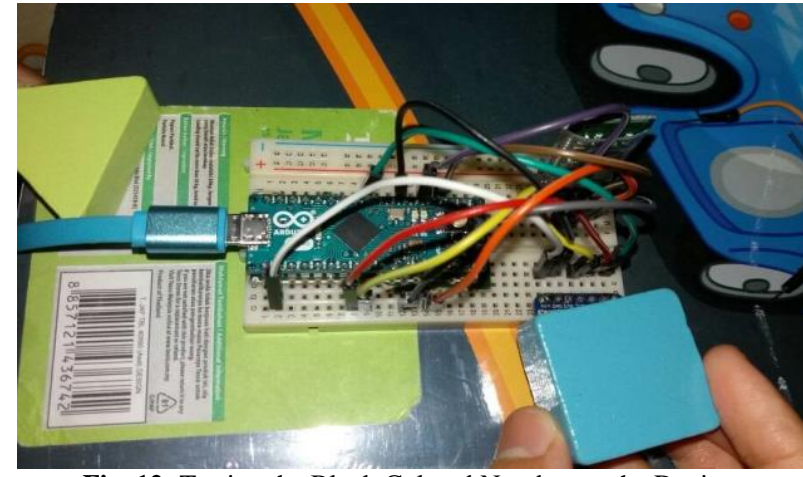

Fig. 12: Testing the Block Colored Number on the Device.

The only way to make the Arduino identify the color of the different frequency is by making average on Red, Green, Blue (RGB) for each color.

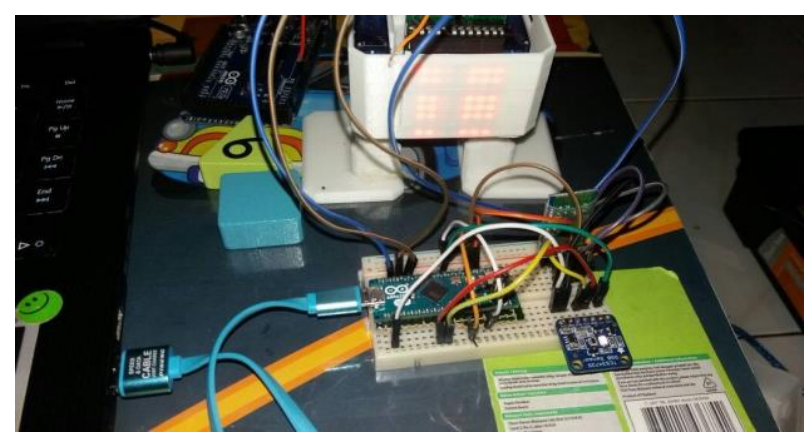

Fig. 13: Testing the Sensor with the MEGO Robot.

Upon the successful on developing the Bluetooth Module, average on RGB, the kit and Arduino App to function properly, combine all three. However, there are problems need to be solved in the hardware designing process. The circuit need to be effortlessly inserted into a child and it connects properly, so the kit will move functionally.

\section{Conclusion}

In conclusion, Mathematics Education Go is a significant revolution compared to conventioanl method of teaching. The project is different from others as it uses the color sensor as the number block hardware. The problems faced when doing this project is mainly on coding and running the simulation. The first problem is that the project used the color sensor as the input. This cause some problems as the library for the sensor do not exist. The second problem is the application maker used to make the app. MIT inventor 2 have a big flaw, which it cannot share data between screens. The error made it difficult to make the apps with the possibility of Bluetooth connection can be made. To solve the research problem, the attendees to a workshop on Arduino are compulsory. The preliminary stage is that the game is only limited to mathematics only. The project is giving impact to children and boosts their motivation to study.

\section{References}

[1] Su CT, Lin CS \& Chiang TL (2008), Systematic improvement in service quality through TRIZ methodology: An exploratory study. Total Quality Management 19, 223-243.

[2] Mullis IV, Martin MO, Foy P \& Arora A (2012), TIMSS 2011 international results in mathematics. International Association for the Evaluation of Educational Achievement.

[3] MR, Bakar ZA \& Ali RM (2012), the impact of video games in children is learning of mathematics. World Academy of Science, Engineering and Technology 6, 968-974.

[4] Gathercole SE \& Alloway TP (2013), Understanding-working memory: A classroom guide. https://www.mrc-cbu.cam.ac.uk/wpcontent/uploads/2013/01/WM-classroom-guide.pdf.
[5] Schmidt G (2017), the best toys that teach kids how to code. https://www.nytimes.com/2017/12/19/smarter-living/kids-toys-forcoding.html.

[6] Rifin R, Fang TE, Abidin AF, Adam A, Majid MA, Zainuddin A, Mohammad SH, Harun MH \& Rizman ZI (2018), Examwiz: A development and implementation of an android based examination. Journal of Fundamental and Applied Sciences 10, 965-976.

[7] Cecílio J, Andrade J, Martins P, Castelo-Branco M \& Furtado P (2016), BCI framework based on games to teach people with cognitive and motor limitations. Procedia Computer Science 83, 74-81.

[8] Sharon H (2016), Code gamer: A review. http://www.parentschoice.org/product.cfm?product_id $=34650 \&$ StepNum $=1$ \&award $=\mathrm{a}$ $\mathrm{w}$

[9] Gardner M (1970), Mathematical games-The fantastic combinations of John Conway's new solitaire game 'life'. Scientific American 223, 120-123.

[10] Brox P, Huertas-Sánchez G, López-Angulo a, Álvarez-Mora M \& Haya I (2016), Design of sensory systems using the platform Arduino by undergraduate Physics students. Proceedings of the IEEE Technologies Applied to Electronics Teaching, pp. 1-6.

[11] Mustapa RF, Abidin AF, Amin AA, Nordin AH \& Hidayat MN (2017), Engineering is fun: Embedded CDIO elements in electrical and electronic engineering final year project. Proceedings of the IEEE 9th International Conference on Engineering Education, pp. $1-6$. 